Recebido: $15 / 05 / 2018$

Aprovado: 08/06/2018

\title{
Operários no Contestado: um estudo sobre os momentos de organização e luta dos trabalhadores da Lumber Company, 1917- 1919.
}

Alexandre Assis Tomporoski*

Resumo: O objetivo deste estudo consiste em investigar algumas das primeiras greves deflagradas na região do Contestado, no planalto catarinense, paralelamente à ampliação do movimento operário nacional, no contexto de 1917 a 1919. As greves originaram-se na Lumber Company, madeireira e colonizadora norte-americana, cuja atuação na região - mediante a expulsão de posseiros e através de uma política despótica em relação à população local - contribuiu decisivamente para a eclosão do Movimento Sertanejo do Contestado (1912-1916). Apenas sete meses após o término dos combates, o primeiro movimento grevista irrompeu na companhia, localizada no município de Três Barras. O texto ampara-se no enfoque proposto por Edward Palmer Thompson, no âmbito da História Social Inglesa. Por conseguinte, a partir das concepções thompsonianas subjacentes, o artigo considera pesquisas realizadas a fontes de natureza jornalística, principalmente da imprensa operária, o que propiciou a análise dos processos relacionados à deflagração de duas greves na Lumber Company, respectivamente nos anos de 1917 e 1919. Os resultados obtidos apontam para uma intensa mobilização dos trabalhadores da Lumber Company, os quais possuíam conexões com outros grupos de trabalhadores, fato que comprova sua articulação em nível nacional. Conclui-se que na região do Contestado, as estratégias de resistência e luta dos mais pobres continuaram em vigência mesmo após o término do movimento sertanejo, apresentando-se na forma de greves e mobilizações operárias, depreendendo-se que compuseram um conjunto mais amplo de mobilizações, devidamente articuladas, que adquiriram relevância nacional no período de 1917 a 1919.

Palavras-chave: História do Contestado; Greves; História do Trabalho.

\footnotetext{
* Professor Permanente do Programa de Mestrado em Desenvolvimento Regional da Universidade do Contestado (UnC). Doutor em História pela Universidade Federal de Santa Catarina. Pós-doutor em Ordenamento Territorial pela Universidad Castilla-La Mancha, Espanha.
} 
Abstract: The aim of this study is to investigate some of the first strikes in the Contestado region in the Santa Catarina Plateau, in parallel with the expansion of the national workers' movement, in the context of 1917-1919. The strikes originated in the Lumber Company, and a North American colonizer whose activities in the region through the expulsion of squatters and through a despotic action in relation to the local population - contributed decisively to the outbreak of the Contestado (19121916) sertanejo movement. Just seven months after the end of the war, the first strike movement broke out at the company, located in the municipality of Três Barras. Materials and Methods: The text is based on the approach proposed by Edward Palmer Thompson in the context of English Social History. Therefore, based on the Thompsonian conceptions underlying it, the article considers results obtained in research to sources of journalistic nature, mainly of the working press, which allowed the analysis of the processes related to the outbreak of two strikes in the Lumber Company, respectively in the years 1917 and 1919. The results obtained point to an intense mobilization of the Lumber Company workers, who had connections with other groups of workers, a fact that proves their articulation at the national level. It is concluded that in the Contestado region the strategies of resistance and struggle of the poorest continued in force even after the end in the sertanejo movement, presenting itself in the form of strikes and worker mobilizations, which, in parallel, comprised a broader set of mobilizations, which were articulated and of national relevance in the context of 1917 to 1919.

Keywords: Contestado History; Strikes; Work History. 


\section{Introdução}

Os estudos sobre a Guerra do Contestado (1912-1916), também denominada de Movimento Sertanejo do Contestado, apresentaram importante expansão nos últimos quinze anos. Não obstante o movimento ter sido abordado por uma ampla gama de interessados no tema, desde os militares que combateram os sertanejos no planalto catarinense, até investigadores acadêmicos, memorialistas, jornalistas, médicos, etc., a partir do início dos anos 2000, verificou-se uma notável ampliação dos estudos sobre a temática. Esse processo esteve relacionado não apenas à ampliação do leque de fontes empregado nas pesquisas e pela sofisticação teórico-metodológica que passou a compor tais estudos, mas, também, por um período de expansão dos programas de pós-graduação em nível nacional, processo que propiciou ampliar e qualificar a produção sobre o Contestado. ${ }^{1}$ Outro fator que marcou essa virada historiográfica foi a adoção de novos parâmetros cronológicos e geográficos, por meio da identificação do contexto de 1912 a 1916 como o período de erupção das tensões sociais, gestadas em décadas anteriores. Da mesma forma, o término dos embates da população sertaneja contra as forças de repressão, não representou o fim dos conflitos entre os mais pobres e as classes dominantes. Em outro cenário, o enfrentamento, a resistência e a luta da população local contra o despotismo do Estado e da Lumber Company continuou.

Poucos meses após o fim dos combates da Guerra do Contestado, irrompeu a primeira greve deflagrada na Lumber Company, em julho de 1917. Até meados de 1919,

\footnotetext{
${ }^{1}$ Acerca da produção recente sobre a temática do Contestado consultar: RODRIGUES, Rogério Rosa. Veredas de um grande sertão: a Guerra do Contestado e a modernização do Exército brasileiro na Primeira República. Tese de Doutorado em História, Universidade Federal do Rio de Janeiro, Rio de Janeiro, 2008; VALENTINI, Delmir José. Atividades da Brazil Railway Company no sul do Brasil: a instalação da Lumber e a Guerra na região do Contestado (1906-1916). Porto Alegre. Tese (Doutorado em História). PUC/RS. Porto Alegre, 2009; ESPIG, Márcia J. Personagens do Contestado: os turmeiros da Estrada de Ferro São Paulo - Rio Grande. Pelotas: Ed. UFPel, 2010; CARVALHO, Miguel. Mundstock. Xaxier de. Uma grande empresa em meio à floresta: a história da devastação da floresta com araucária e a Southern Brazil Lumber and Colonization (1870-1970). Tese (Doutorado em História). Universidade Federal de Santa Catarina. Florianópolis, 2010; TOMPOROSKI, Alexandre Assis. "O polvo e seus tentáculos": A Southern Brazil Lumber and Colonization Company e as transformações impingidas ao planalto contestado, 1910-1940. Tese de Doutorado em História, UFSC, Florianópolis, 2013; DALLANORA, Cristina. Conflito de terra e formas de apropriação no Meio-Oeste Catarinense: o caso de Vivaldino Silveira de Ávila (19161930). Conversas \& Controvérsias, v. 4, p. 127-148, 2017; POYER, Viviani. Fronteiras de uma guerra: diplomacia e política internacional em meio ao movimento social do Contestado, 1907-1918. Tese (Doutorado em História). UFSC. Florianópolis, 2018.
}

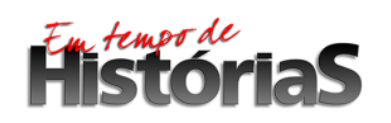


a tensão entre os trabalhadores, a polícia local e a companhia manteve-se elevada, concomitantemente ao período de maior agitação do movimento operário nacional.

Deste modo, o presente artigo objetiva analisar o período de intensa agitação suscitado pelas greves deflagradas pelos trabalhadores da Lumber Company (19171919). Busca-se compreender as motivações daqueles movimentos e suas relações com o movimento operário nacional. O objeto converge, por um lado, aos estudos relacionados à história do Contestado e, por outro, às abordagens sobre a história do trabalho no Brasil. Sua singularidade permite ampliar o foco de análise sobre o território do Contestado, expandindo a cronologia tradicional associada aos combates do movimento sertanejo, além de contribuir para a integração dos movimentos grevistas deflagrados no planalto catarinense em um arcabouço de análise mais amplo, de âmbito nacional.

\section{Contribuições da História Social Inglesa}

As propostas teóricas e metodológicas, oriundas da história social inglesa, disponibilizaram instrumentos de análise sofisticados, que influenciaram o estudo de diversos temas, a partir de uma perspectiva historiográfica que valorizou a óptica dos "de baixo".

Edward Palmer Thompson, nome destacado do grupo britânico, insuflou transformações teóricas. Uma das proposições centrais do autor britânico aponta para a ideia de que o proletariado não consistiu em uma simples resultante automática da industrialização. Ao contrário, para Thompson, a indústria moderna resultou do processo histórico da luta de classes, de tal modo que o reconhecimento dos próprios trabalhadores como classe situa-se na gênese da indústria moderna. Sendo assim, a formação da classe operária é condição necessária para o processo de industrialização e não consequência desse processo.

Sob essa perspectiva, o desenvolvimento da indústria conecta-se a uma alteração nas atitudes e comportamentos dos trabalhadores, os quais, ao se auto-reconhecerem como uma classe (em oposição ao patronato) defendem objetivos, tais quais: regulamentação da jornada de trabalho; elevação da remuneração recebida pelos serviços prestados; condições adequadas de saúde e segurança no trabalho, etc. Portanto, esse processo fomenta a constituição de organizações dos trabalhadores e o estabelecimento por meio da luta de classes - de novas relações entre os operários e os capitalistas. 
Dentre as transformações suscitadas pela perspectiva thompsoniana, destaca-se a ideia de que não é possível delimitar as explicações sobre a classe considerando apenas os acontecimentos relacionados ao trabalho ou à vida econômica. Na realidade, é preciso considerar uma diversidade de fatores sociais, culturais, elementos da vida e das tradições dos indivíduos. Tais elementos assumem o protagonismo da análise. Consequentemente, do pensamento de Thompson emerge uma crítica contumaz ao determinismo econômico e à noção de classe como efeito direto do modo de produção, o que, por sua vez, exige uma reconsideração da noção de consciência de classe. A consciência de classe como proveniente do processo histórico de auto reconhecimento, divergindo da noção de que a consciência de classe resultaria do modo de produção. Assim, a classe só pode ser definida dentro de um processo histórico. Ela é resultado de suas próprias lutas e constitui a si própria.

Essa mudança de perspectiva deu origem a interpretações que passaram a considerar "os de baixo" como agentes de suas próprias vidas e detentores da capacidade de atuação política, mesmo quando não se adequem aos padrões tradicionais das organizações, inclusive em suas relações tecidas no cotidiano, lúdicas ou laborais.

Nesse sentido, propõe-se a investigação da organização e atuação dos trabalhadores da Lumber Company a partir dessa perspectiva, supondo-se que os mesmos identificaram a existência de uma relação comum, marcada por profunda desigualdade - expressa, principalmente, pelas disputas relacionadas aos acidentes de trabalho ocorridos na empresa - o que fomentou a concepção de que seus interesses eram compartilhados por todos os trabalhadores, independente da origem étnica, e eram antagônicos aos interesses da empresa e das forças de repressão do Estado. Tal concepção foi decisiva para sua organização e contraposição aos interesses de seus patrões (THOMPSON, 1988).

\section{A chegada do capital estrangeiro ao Contestado}

Nas primeiras décadas do século XX, a região do planalto norte de Santa Catarina era caracterizada por profunda instabilidade e tensão social. Dentre os elementos que influenciaram aquela configuração, destaca-se o processo de inserção de empresas estrangeiras ligadas ao Sindicato Farquhar. O conglomerado de empresas era controlado pelo magnata norte-americano Percival Farquhar, que adquiriu, em 1906, a Companhia 
Estrada de Ferro São Paulo - Rio Grande. Aquela empresa, ligada à Brazil Railway Company, obteve a concessão para construir a ferrovia que iria atravessar a região do Contestado (SINGER, 1998, p.381).

A estrada de ferro conectava Sorocaba (SP) a Santa Maria (RS). No ano de 1910, foram entregues ao tráfego os trezentos e oitenta quilômetros referentes ao trecho catarinense, entre União da Vitória (PR) e o rio Uruguai. Em 1917, foi concluído o ramal que ligaria União da Vitória e a cidade portuária de São Francisco do Sul, em Santa Catarina, permitindo o escoamento rápido e eficiente da erva mate e da madeira exploradas na região do Contestado (MACHADO, 2004, p.142).

Por meio do contrato de construção da estrada de ferro, a Brazil Railway Company recebeu a concessão para exploração das terras marginais à linha tronco da ferrovia, numa extensão de até quinze quilômetros. Objetivando explorar aquelas terras, serrar a madeira e vender os lotes aos imigrantes europeus, no ano de 1910 foi instalada, em Três Barras, a Southern Brazil Lumber and Colonization Company.

Com o início de suas atividades, em novembro de 1911, a Lumber Company passou a desenvolver um processo inovador para a exploração da madeira. Para tal fim, seu instrumento foi um complexo industrial de proporções ímpares, tornando-se a maior madeireira da América do Sul (CARVALHO, 2010, p. 29).

Visando aperfeiçoar o processo de extração da madeira, foram construídos ramais com extensão de até trinta quilômetros, que partiam da serraria e alcançavam os pinhais mais densos. Concluídos os trilhos, as composições, municiadas com poderosos guinchos movidos a vapor comprimido, avançavam sobre as matas. As toras que jaziam no chão, abatidas pelas turmas de trabalhadores que haviam realizado a derrubada, eram então arrastadas por cabos de aço de até cem metros de comprimento. Em seguida, as toras eram recolhidas aos vagões e transportadas até a serraria, onde eram serradas, classificadas e armazenadas. Em seguida, eram transportadas por trem aos portos de São Francisco do Sul e Paranaguá e, em seguida, ao exterior. Contudo, uma parcela expressiva da produção da serraria era destinada ao Rio de Janeiro, São Paulo e Curitiba, demonstrando que a Lumber atendia a uma demanda de mercado que existia no Brasil, disponibilizando madeira serrada que fomentou a urbanização e industrialização do centro sul (CARVALHO, 2010, p.100).

Nos anos subsequentes, a empresa também desenvolveu atividades ligadas ao beneficiamento e comercialização da erva mate. Balancetes contábeis do ano de 1917

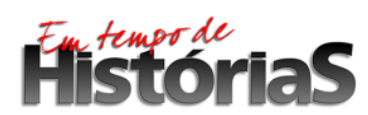


evidenciam gastos realizados na compra de erva mate de terceiros, bem como despesas com a construção de barracões para armazenamento do produto, no porto de São Francisco do Sul. Outro indicativo relevante consiste na utilização de dois vapores pela empresa: o "Três Barras" e o "Porto Velho", embarcações de médio porte, carregadas de erva mate, que navegavam pelos rios da região. Além disso, a Lumber mantinha um porto no município de Três Barras, onde aquelas embarcações atracavam, suprido por mão de obra permanente, evidenciando a existência de um comércio dinâmico e financeiramente significativo.

\section{Os trabalhadores da Lumber Company}

A partir da análise de dados extraídos de processos judiciais decorrentes de acidentes de trabalho, ocorridos na Lumber Company, efetivou-se o delineamento do perfil da mão de obra empregada pela companhia (TOMPOROSKI, 2013, p.119). Apurou-se que a proporção entre trabalhadores de origem nacional e estrangeira aproximava-se do equilíbrio, isto é, os trabalhadores de origem nacional representavam quase $53 \%$ (cinquenta e três por cento) da mão de obra da companhia, enquanto os trabalhadores de origem estrangeira correspondiam a pouco mais de $47 \%$ (quarenta e sete por cento).

Ao considerar o local de origem dos trabalhadores nacionais e estrangeiros, constata-se que $90 \%$ (noventa por cento) dos trabalhadores nacionais eram oriundos dos estados de Santa Catarina e Paraná. É necessário destacar que parcela significativa dos trabalhadores considerados catarinenses e, principalmente, paranaenses, era, na verdade, constituída de imigrantes, principalmente poloneses, assentados em colônias pelos dois estados. Esse fato permite afirmar que o número de imigrantes era consideravelmente superior. Ao analisar o local de origem dos trabalhadores estrangeiros, verifica-se a preponderância de trabalhadores provenientes da Polônia, representando quase $50 \%$ (cinquenta por cento) dos trabalhadores de origem estrangeira; os trabalhadores oriundos de Portugal, correspondendo a aproximadamente $15 \%$ (quinze por cento); os trabalhadores oriundos da Rússia representando cerca de $10 \%$ (dez por cento), e os demais trabalhadores estrangeiros oriundos da Alemanha, Áustria, Estados Unidos, Espanha, Holanda, Inglaterra e Ucrânia. Ressalta-se, também, que aproximadamente 65\% (sessenta 
e cinco por cento) dos trabalhadores estrangeiros eram de origem eslava, grupo étnico proveniente do leste europeu.

O número de trabalhadores empregados na Lumber Company apresentou significativa variação ao longo do tempo. Durante o período de construção das instalações da madeireira, o contingente foi bastante superior, decrescendo conforme se aproximava o término daquela etapa e o início das atividades operacionais. No ano de 1915, o número de trabalhadores empregados no beneficiamento da madeira correspondia a seiscentos e quinze, além daqueles envolvidos no corte e transporte das toras na mata. (DIACON, 1991, p. 55). Conquanto o longo período de funcionamento da companhia, o acervo documental fragmentado não permite um levantamento exato do número de trabalhadores empregados no decorrer de todo o período, sendo razoável a afirmação de que, ao longo dos anos de funcionamento, a empresa manteve continuamente entre quatrocentos e seiscentos trabalhadores (VALENTINI, 2009, p. 163).

Um aspecto que merece destaque refere-se à existência de uma divisão étnica do trabalho dentro da Lumber. É plausível supor que havia uma predileção, por parte da empresa, pela contratação de imigrantes europeus para o desempenho de atividades associadas ao processo industrial, que exigiam maior grau de especialização, tal qual no interior da serraria ou na condução das máquinas locomotivas. De modo recorrente, tais funções não foram preenchidas em atendimento aos critérios técnicos, pois os dados provenientes das ações trabalhistas evidenciam uma quantidade significativa de analfabetos entre os imigrantes que desenvolviam tais atividades. Além disso, muitos eram trabalhadores rurais em seus países de origem, não viviam em áreas urbanas, tampouco trabalhavam em fábricas.

Depreende-se que as vagas - sempre que possível - eram direcionadas aos imigrantes em detrimento dos trabalhadores nacionais, tendo como base uma retórica etnocêntrica, a qual acompanhou a elaboração de identidades étnicas, especialmente nesse período, e estabeleceu o caboclo como "o outro", o oposto do imigrante europeu. Este trazia consigo um ethos do trabalho, característica marcante e classificatória; aquele era reconhecido pela preguiça e indolência (SEYFERTH, 2000, p. 81-109).

Os trabalhadores da Lumber, oriundos de grupos étnicos distintos, vivenciavam, nos acidentes de trabalho, um quadro de constante precariedade, algo comum a todos. Tanto no serviço das matas, quanto no processo de beneficiamento da madeira, os acidentes se multiplicavam. Assim, obviamente tais acidentes não reconheciam a etnia do 
trabalhador, representando riscos compartilhados por todos os trabalhadores da Lumber. Nesse contexto, torna-se assaz relevante destacar a existência de uma intensa circulação de informações entre os trabalhadores da empresa. As informações sobre os acidentes recentemente ocorridos, o histórico de acidentes anteriores e as consequentes ações trabalhistas, representavam interesses comuns que fomentavam a interlocução. Tal interação, mesmo quando imposta por necessidades imediatas, proporcionou a construção de um saber prático (PAOLI, 1991, p. 27-41) acerca dos acidentes e de suas condições de trabalho, seus problemas e demandas, processo que orientou decisões e posturas com relação ao trabalho e à empresa. A circulação da palavra e a troca de informações fundamentais em meio a uma complexa rede de pessoas, proporcionou a construção de um conhecimento comum, que se transformou em fator preponderante, tanto para a transposição de barreiras étnicas, quanto para o estabelecimento dos contornos de futuras formações de classe.

Desse modo, torna-se plausível afirmar que, não obstante outros procedimentos executados pela empresa que culminavam em opressão aos seus empregados, os acidentes de trabalho consistiram em elemento precípuo aos trabalhadores da Lumber, a partir dos quais identificaram a existência de uma relação comum, marcada por profunda desigualdade, o que fomentou a concepção de que seus interesses eram compartilhados por todos os trabalhadores, independente da origem étnica. Tal concepção foi peremptória para sua organização e contraposição aos interesses de seus patrões (THOMPSON, 1988).

Conquanto as diferenças étnicas e os conflitos decorrentes, cabe destacar que a primeira leva de imigrantes chegou à região em 1829, em Rio Negro, Paraná. Naquele contexto, muitos imigrantes e descendentes passaram a amalgamar-se à população pobre nacional, num processo denominado acaboclamento (MACHADO, 2004, p. 336).

Desse modo, é coerente considerar que as experiências compartilhadas pelos trabalhadores da Lumber Company intensificaram seus interesses em comum, proporcionando trocas, conflitos e alianças, que se manifestaram em seu cotidiano e no conjunto de suas relações sociais. Esse processo, em essência uma reação às péssimas condições de trabalho, cuja materialização se dava na forma de acidentes de trabalho, induziu, no decorrer dos anos, a formação de uma identidade operária e contribuiu decisivamente para obliterar eventuais barreiras étnicas (TOMPOROSKI, 2006, p. 48). 


\section{Momentos de organização e luta}

Transcorrido menos de um ano após o término dos conflitos do Movimento Sertanejo do Contestado (1912-1916), os trabalhadores da Lumber Company desenvolveram outra forma de expressão reivindicatória, que se manifestou por meio dos movimentos grevistas por eles deflagrados. No mês de julho de 1917, os trabalhadores de todo o Brasil estavam agitados e as notícias da deflagração de greves incitavam novos movimentos. As notícias circulavam pelos jornais, os quais difundiam os acontecimentos de São Paulo e informavam que a greve geral havia chegado, por exemplo, ao Paraná, “(...) havendo repercussão de tal movimento em Três Barras, onde se encontra instalada a importante empresa de serraria - a Lumber" (TIMONEIRO DO NORTE, 25/07/1917). As notícias também transitavam nos trens, que incessantemente chegavam e partiam conduzidos por trabalhadores que pertenciam à categoria dos ferroviários, historicamente caracterizada pelo alto grau de politização, e ampla disseminação das informações.

Os trabalhadores da Lumber Company eram contínua e gradativamente pressionados pela longa jornada de trabalho - que poderia atingir a dez horas diárias - e expostos a elevados riscos de acidentes, os quais ocorriam em todo o processo industrial da empresa, independente da origem étnica ou da hierarquia salarial, e representavam uma ameaça constante no cotidiano dos trabalhadores. Além disso, às empresas não era atribuída nenhuma responsabilidade legal, pois foi apenas no ano de 1919, com a aprovação da lei de acidentes de trabalho, que os empregadores passaram a ser legalmente responsabilizados pelos acidentes e obrigados a assumir o ônus, disponibilizando tratamento médico e hospitalar e indenizando aqueles trabalhadores que tivessem redução ou perdessem a capacidade para o trabalho.

Concomitantemente, os efeitos decorrentes da Primeira Guerra Mundial repercutiam para o operariado em todo o mundo e, inclusive, no Brasil. Alguns setores enfrentavam a redução ou interrupção das vendas para o exterior, resultando no fechamento de fábricas e na demissão de operários. A retração dos capitais e do crédito configurou esse cenário. Ademais, o decréscimo da produção agrícola europeia compeliu os países daquele continente a comprar gêneros de primeira necessidade em outras regiões, resultando na carestia e aumentando a inflação.

A greve geral de 1917 foi um movimento espontâneo do proletariado, destituída de interferências direta ou indireta. Foi uma manifestação explosiva, após um longo período

\section{Hitstorias}


da vida tormentosa que então levava a classe trabalhadora. A carestia do indispensável à subsistência do povo trabalhador tinha como aliada a insuficiência dos ganhos; a possibilidade de legítimas reivindicações a imprescindíveis melhorias da situação laboral era coibida por sistemática reação policial; as organizações dos trabalhadores eram constantemente assaltadas e impedidas de funcionar; os postos policiais superlotavam-se de operários, cujas residências eram invadidas e devassadas; qualquer tentativa de reunião de trabalhadores provocava a intervenção brutal da polícia. A reação imperava nas mais odiosas modalidades. O ambiente proletário era caracterizado por incertezas, sobressaltos, angústias. A situação tornava-se insustentável.

Compartilhando o mesmo espaço, costumes e práticas, a população não-operária também convivia com dificuldades semelhantes às enfrentadas pelos trabalhadores. No caso da greve geral de 1917, a carestia, que atingia toda a população - evidentemente causando maior impacto sobre as camadas mais pobres - consistiu em fator preponderante para a mobilização. Isso evidencia parcialmente os laços que uniam os diversos segmentos da população aos interesses da classe trabalhadora, e expõe uma questão subjacente, qual seja, a participação política na Primeira República, que encontrava nas organizações e manifestações de trabalhadores a sua forma de expressão, em um contexto político partidário limitado pelo controle oligárquico. No âmbito de São Paulo, a grande conquista do movimento de 1917 foi o reconhecimento do movimento operário como instância legítima, e, da classe trabalhadora, como ator social e interlocutor. Analogamente às dificuldades enfrentadas pelos trabalhadores de São Paulo, os trabalhadores da Lumber Company compartilhavam a mesma insegurança estrutural (SAVAGE, 2004, p.33), ou seja, a incerteza da vida diária, mediante o aumento da exploração e a crescente dificuldade de sobrevivência. Os trabalhadores da Lumber Company, tal qual o operariado do centro sul e de outras regiões do país, declararam estado de greve.

No entanto, apesar dos problemas comuns e da insatisfação compartilhada por trabalhadores de todas as regiões do país, houve especificidades que motivaram a deflagração da greve na Lumber Company. É preciso considerar que, além das reivindicações imediatas dos trabalhadores, a empresa encontrava-se no epicentro de uma série de questões vultosas que influenciaram o início do movimento grevista de 1917.

Em 20 de outubro de 1916, fora assinado o Acordo de Limites entre os estados do Paraná e de Santa Catarina, que transferiu para o controle do estado catarinense todos os 
territórios ao sul dos rios Negro e Iguaçu, transformando Três Barras - até então município do Paraná - em distrito do município catarinense de Canoinhas. O resultado imediato foi a exoneração de Dídio Augusto do cargo de prefeito de Três Barras, cargo extinto pela mudança. Dídio fora o primeiro prefeito da Três Barras paranaense, tendo sido reeleito para o cargo, e sempre apresentara postura de apoio aos trabalhadores da Lumber Company e de combate aos excessos cometidos pela empresa. A insurreição dos trabalhadores possivelmente foi influenciada por essa mudança. Dois meses após a deflagração da greve na Lumber Company, as mudanças no cenário político local demonstravam que a situação dos trabalhadores tenderia a agravar-se. No mês de setembro de 1917, o médico da Lumber Company, Oswaldo de Oliveira, foi nomeado intendente distrital de Três Barras, cargo que lhe atribuía, inclusive, a prerrogativa de nomear autoridades locais, tal qual o subdelegado de polícia, fato que possibilitou à Lumber legitimar e amplificar seu domínio sobre aquele território.

Intrinsecamente relacionado ao movimento grevista ocorrido no ano de 1917 na companhia Lumber, desenvolveu-se a formação de uma Liga Operária, por meio da qual os trabalhadores e a companhia chegaram a um acordo que pôs termo a greve, legitimado em documento assinado pelo diretor da empresa.

Apenas seis meses depois, em abril de 1918, começou a circular pela região do planalto norte catarinense um novo jornal. Fundado por Dídio Augusto, que também ocupava a função de redator-chefe, o jornal recebeu o sugestivo nome de "Liberdade" (TIMONEIRO DO NORTE 06/04/1918), o qual era impresso no município paranaense da Lapa e distribuído em toda a região. O advento da circulação do periódico e a constituição da Liga Operária representaram balizas importantes no processo de materialização das experiências dos trabalhadores da Lumber Company em âmbitos institucionais.

Certamente esses fatos colaboraram para elevar sobremaneira a capacidade de organização, mobilização e luta dos trabalhadores da companhia. Consequentemente, os grevistas obtiveram um acordo com o diretor da empresa. Todavia, nos meses seguintes, o diretor da Lumber recusou-se a cumprir os compromissos assumidos ao término do movimento grevista de 1917 (A PÁTRIA, 01/09/1918). Cabe salientar que no decorrer do ano de 1918, o país encontrava-se em estado de sítio. Naquele contexto, as autoridades de Três Barras realizaram ferrenha perseguição aos integrantes da diretoria da Liga Operária. 
Em agosto de 1918, a polícia local - chefiada pelo subdelegado Theófilo Becker prendeu, na estação de Três Barras, um viajante do trem oriundo de Curitiba, o qual a polícia suspeitava ser o presidente da Liga Operária de Três Barras, e que havia permanecido muitos dias na capital paranaense. A atitude foi considerada, pelo redator do jornal A Pátria, do município vizinho de Mafra, uma "perseguição a operários brasileiros que se conservam em atitude pacífica” (A PÁTRIA, 01/09/1918).

Seis meses após os episódios de perseguição policial contra os membros da Liga Operária, nova greve foi deflagrada pelos trabalhadores da Lumber Company, em março de 1919. Além da insatisfação pelo não cumprimento do acordo firmado em 1917, o objetivo principal consistia no combate à atuação do chefe do serviço sanitário da empresa e intendente distrital de Três Barras, o médico Oswaldo de Oliveira. Ele fora acusado de perseguição política contra os trabalhadores, que exigiam sua retirada do cargo de intendente.

E eis que (...) certo número de operários, no momento insubstituíveis, lançaram o ultimatum: 'Sai Oswaldo de Oliveira e demais autoridades, ou pára a Lumber!'. Recebida tal imposição pelo Dr. Sherman Bishop (...) com o espírito de justiça e inteireza de caráter que lhe conhecemos (...) admoestou os paredistas, fazendo ver a nenhuma razão de sua mesquinha atitude; e, depois, convencendo-se de não colher resultados por esse meio lavrou a sentença: 'Oswaldo é e será o médico da Lumber; as autoridades dignas de acatamento têm, pois todo meu prestígio, pare, muito embora, a Lumber! Grevistas ao olho da rua! (O DEMOCRATA, 23/03/1919).

As hostilidades infligidas ao médico têm duas vertentes principais. A primeira está ligada à sua participação nas disputas judiciais entre a Lumber e seus operários, fornecendo à empresa laudos e atestados que favoreciam a mesma em detrimento dos interesses dos trabalhadores, resultando na redução das indenizações ou, inclusive, na ausência de quaisquer pagamentos às vítimas (TOMPOROSKI, 2006). No entanto, como a lei de acidentes de trabalho entrou em vigor em 15 de janeiro de 1919 [Decreto 3.724] e foi regulamentada apenas em 12 de março [Decreto 13.498], é plausível afirmar que os trabalhadores não tiveram tempo hábil para identificar a participação viciada do médico nas ações judiciais. Em outra vertente, conforme exposto anteriormente, Oswaldo havia sido nomeado intendente distrital de Três Barras em 1917, em substituição à Dídio Augusto, ex-prefeito da Três Barras paranaense, e ativo militante a favor dos direitos dos trabalhadores e contra o modo de atuação da empresa norte-americana.

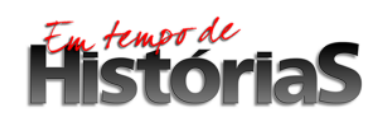

(PPGHIS/UnB) №. 32, Brasília, Jan - Jul 2018 ISSN 2316-1191 
É admissível afirmarmos que a mobilização estava relacionada tanto àquela substituição quanto a perseguição política empreendida pela empresa contra os membros da Liga Operária e ao próprio Dídio Augusto, mediante atuação do médico/intendente e do subdelegado. Este, inclusive, solicitou apoio da força pública situada em Canoinhas, a qual seguiu para o distrito de Três Barras (O DEMOCRATA, 23/03/1919), com o objetivo de reprimir o movimento grevista. No dia anterior, o jornal Gazeta do Povo, de Curitiba, havia publicado um telegrama recebido de Três Barras:

A situação aqui é muito grave. A Companhia Lumber suspendeu seus trabalhos. Os empregados dessa companhia americana se viram na contingência de pedir proteção ao embaixador (...) contra as arbitrariedades catarinenses daqui. $\mathrm{O}$ autor da grave situação em que nos achamos é o Sr. Becker, delegado catarinense. Os ânimos estão exaltados. Foi formada uma comissão de reação. (a) - A comissão. (GAZETA DO POVO, 16/06/1919).

A atuação do subdelegado em prol dos interesses da companhia e, mais especificamente, a favor dos interesses de Oswaldo de Oliveira, consistia em algo recorrente desde sua nomeação, em setembro de 1917. A escalada das tensões iniciou em julho de 1917, quando a primeira greve fora deflagrada. Seu encerramento, mediante um acordo - descumprido pelo diretor da Lumber Company - não significou o fim das tensões, pelo contrário, com a fundação do jornal "Liberdade" e a perseguição imposta aos membros da Liga Operária de Três Barras, resultaram no agravamento da situação e consequente disseminação de práticas violentas pela polícia e pelos homens do corpo de segurança da empresa.

A notícia da greve deflagrada na Lumber, em março de 1919, foi publicada no jornal anarquista A Plebe, de São Paulo, e fornece uma série de informações relevantes.

Três Barras é um posto ferroviário, uma vila, lugar onde a célebre Companhia Lumber desenvolve e estende os seus tentáculos, a sugar nosso sangue, isto é, daqueles que aqui laboram. Tivemos aqui, em tempo, Liga Operária, para defesa dos nossos direitos, mas a fúria dos patrões, secundada pela polícia, a mesma polícia forjadora de greves com o intuito de perseguir os membros da Liga e dissolvê-la, inventou espancamentos, abriu inquérito, amedrontou os operários com ameaças de deportação e processo, proclamou aos quatro ventos que a Liga jamais funcionaria sem o seu consentimento e que não respeitaria habeas corpus, ainda que viessem aos mil. Três Barras, durante meses, parecia uma praça de guerra. A polícia rondava noitadas inteiras, e a

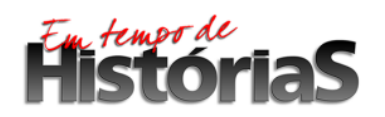

(PPGHIS/UnB) №. 32, Brasília, Jan - Jul 2018 ISSN 2316-1191 
estação ferroviária, onde devia desembarcar o nosso presidente, então em Curitiba, foi esse tempo todo guarda pelos beleguins, de armas em prontidão. E tudo se foi. A Liga, assim perseguida, foi definhando, e hoje dela só restam o nome e o triste casebre onde funcionou, e uns poucos sócios que (...) prosseguem na campanha (A PLEBE, 24/05/1919).

A acusação de que a polícia local era "forjadora de greves", coaduna-se com notícia publicada no jornal A Pátria, quando da prisão do presidente da Liga Operária, anteriormente referenciada. Uma greve forjada costumava oferecer a justificativa necessária para o desencadeamento da repressão.

A acusação do jornal anarquista de que a Companhia Lumber teria, inclusive, tramado um pretenso incêndio, encontra respaldo nas informações existentes sobre o sinistro. Por volta do meio-dia do dia 14 de setembro de 1917, um incêndio alastrou-se em uma das estufas utilizadas pela empresa no processo de secagem da madeira serrada. Os galpões foram esvaziados e os materiais inflamáveis foram retirados. Não houve um laudo conclusivo sobre as causas do incêndio, o qual foi incluído, pelos trabalhadores, no rol de embustes criados pela empresa para desencadear a repressão. A propósito, é interessante atentar para o fato de que o incêndio, mesmo tendo causado grande balbúrdia na localidade - apitos da fábrica, mobilização de vizinhos para retirada dos materiais inflamáveis, utilização de mangueiras, etc. - resultou em prejuízo irrisório, de apenas $80 \$ 000$ (oitenta mil réis) (O TIMONEIRO DO NORTE, 23/09/1917).

A abertura de inquéritos, e, principalmente, a ameaça de deportação e indiciamento, consistiam em expedientes inexoráveis contra um significativo contingente de trabalhadores estrangeiros. Tais expedientes eram especialmente eficientes em função da política de favorecimentos do sistema judiciário em prol da Lumber Company.

Presume-se que a preocupação do staff da companhia não recaía exclusivamente sobre os movimentos reivindicatórios, mas também na existência e fortalecimento da Liga Operária, que representava um recurso para encaminhamento das demandas dos trabalhadores da empresa.

Assim, submetida à contínua pressão impingida pela companhia, a Liga Operária de Três Barras sucumbiu. A atuação da polícia local, articulada aos interesses da empresa, não representava fato novo, em decorrência da prática de atividades espúrias, ou da vigilância ostensiva, na localidade, transformando-a em "praça de guerra". 
De maneira geral, a repressão consistiu na principal prática adotada pelo Estado em relação aos trabalhadores na Primeira República, em todas as regiões do país, havendo infindáveis relatos acerca da atuação da polícia em harmonia aos interesses dos patrões, visando à repressão aos operários. No entanto, essa convergência de intenções não se configurou em uma política deliberada, mas em uma espécie de livre mercado, onde o acesso patronal aos serviços policiais era diretamente proporcional ao volume de capital das empresas e aos contatos e relacionamentos pessoais entre empregadores e agentes públicos influentes (VARGAS, 2004, p. 105). Todavia, a privatização da repressão não foi necessariamente incompatível com a institucionalização da repressão pelo Estado. Também é razoável admitirmos que em localidades afastadas, fora do eixo Rio - São Paulo, - tal qual no caso do planalto norte de Santa Catarina - a atuação da polícia poderia apresentar aspectos diferenciados, com graus de legalidade e autonomia variáveis, conforme determinações regionais ou locais, porém, de modo geral, "a repressão estava à disposição para quem pudesse obtê-la" (VARGAS, 2004, p. 103).

O fato do diretor da Lumber Company afirmar que a Liga Operária de Três Barras não funcionaria sem o seu consentimento e que, tampouco, respeitaria habeas corpus, é sintomático em relação ao amplo domínio da empresa sobre a região, o que sugere ingentes dificuldades enfrentadas pelos trabalhadores em seu processo de organização e mobilização.

A ameaça de lockout (uma greve patronal que resulta na paralisação dos trabalhos da empresa), aliada à repressão estabelecida desde o término do movimento grevista de 1917, resultou na interrupção da greve.

No entanto, no dia $1 .^{\circ}$ de junho de 1919 ,

Declararam-se em greve os operários da Companhia Lumber, em Três Barras, exigindo aumento de salário e diminuição de horas de serviço, que querem sejam oito. O superintendente da Companhia, um tal Bishop, querendo atemorizar os trabalhadores, declarou paralisar os serviços por três a cinco meses e considerar dispensados todos os operários que tomarem parte do movimento (A PLEBE, 21/06/1919).

Novamente, a ameaça de lockout recaía sobre os trabalhadores, que lutavam por aumento de salário e diminuição da jornada de trabalho, bandeiras desfraldadas pelo operariado nacional em diferentes regiões do país naquele contexto.

Outro aspecto crucial que contribuiu para a agitação dos trabalhadores da Lumber e que compunha o rol de reivindicações referia-se às condições de trabalho. Os frequentes 
e graves acidentes resultavam na precarização das condições de trabalho e os trabalhadores padeciam com ferimentos graves e com o convívio da onipresença de acidentes fatais. Tudo isso sem que a companhia norte-americana assumisse suas responsabilidades legais (DIACON, 1991, p. 51).

Na esteira criada pela mobilização dos trabalhadores, a Liga Operária ressurgiu. A repressão aos seus membros e ao seu funcionamento resultou em um retrocesso temporário, contudo, conforme o momento fosse favorável à organização dos trabalhadores, ela se reerguia, aproveitando-se, inclusive, da onda de reivindicações e mobilizações que que se propagava em todo o país.

A Liga Operária de Três Barras, que tinha sido forçada a fechar por falta de companheiros dispostos a sustentá-la e devido às perseguições brutais da polícia, reabriu sua sede, tendo a sua primeira reunião uma concorrência desusada. (A PLEBE, 21/06/1919).

O fortalecimento do movimento grevista agravou a tensão naquele início de junho de 1919. No âmago dos acontecimentos, o ex-prefeito de Três Barras, redator do Jornal Liberdade e obstinado contendor dos despotismos da Lumber Company, Dídio Augusto, foi preso, ao discursar para os trabalhadores em greve:

Por ter feito um discurso veemente em favor dos operários em greve (1919), quando de passagem por Três Barras (eu morava em Rio Negro), fui preso em Canoinhas (...) até o dia seguinte, quando fui escoltado por soldados (viagem feita de carro tirado por dois cavalos) para a cadeia de Três Barras (onde fui prefeito eleito e reeleito). No dia seguinte, ainda escoltado por duas praças, sob o comando de um sargento, fui conduzido para a cadeia de São Francisco do Sul. Assim passei quatro dias, perturbado no meu direito de ir e vir, e quatro noites, literalmente sem dormir, mas sem ficar abatido (AUGUSTO, 1994, p. 08).

Além das razões expostas para a Lumber Company livrar-se de Dídio Augusto, outra questão fundamental obscurecia aqueles dias extremamente conturbados. Dídio não fora preso exclusivamente em represália ao discurso proferido aos trabalhadores, mas também porque mantinha - na condição de advogado - ação cível contra a companhia (TOMPOROSKI, 2013, p.167).

Entretanto, Dídio Augusto não foi a única vítima de perseguição durante a agitação dos trabalhadores. O engenheiro da companhia, Antonio da Silva Vianna, que proferiu críticas contra as autoridades de Três Barras e a atuação de alguns altos funcionários da

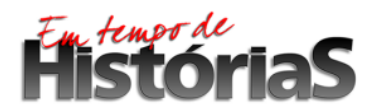


empresa, também foi alvo de represálias da Lumber. Vianna foi procurado pelo Diretor da Lumber, Sr. Bischop, o qual lhe solicitou que organizasse uma comissão de negociação com os trabalhadores, apesar de Viana não se relacionar diretamente com os organizadores do movimento.

Inesperadamente, Vianna foi preso por ordem do delegado regional, permaneceu incomunicável por mais de dois dias, e não fora enviado à cadeia de São Francisco do Sul - juntamente com Dídio Augusto - devido à intervenção de um policial local o qual afirmou que ele não participara diretamente do movimento. Após ser libertado, dirigiu-se até o escritório da companhia, onde descobriu que também havia sido demitido. Ao inquirir o diretor acerca de sua demissão, aquele "declarou que me dispensava porque eu havia tomado parte no movimento, quando lá estive a mando do próprio Bischop" (GAZETA DO POVO, 18/06/1919). Além da demissão, o engenheiro tornou-se pessoa indesejável entre os trabalhadores, os quais consideravam que ele havia "traído a nossa causa", e, por conseguinte, publicaram seu nome nas páginas do Jornal A Plebe, como aviso aos trabalhadores de outras regiões para que nele não confiassem. (A PLEBE, 21/06/1919).

As denúncias do engenheiro preso e demitido eram direcionadas às autoridades do distrito de Três Barras:

\footnotetext{
Desse modo fui traído covardemente, pois confiando em suas palavras foi onde acedi ao seu convite em confiança, sendo afinal como prêmio de minha obediência vergonhosamente traído, tudo por causa da política e pelo fato de sempre ser contra as explorações feitas na Lumber por meia dúzia de parasitas. (GAZETA DO POVO, 18/06/1919).
}

Entre as críticas emanadas contra a atuação da Lumber e às autoridades por ela cooptadas, Vianna denunciava a cobrança abusiva realizada pelo escrivão do Registro Civil, para o fornecimento de um salvo conduto, com preço seis vezes superior ao estabelecido nos municípios vizinhos; e a má fé do responsável pelo serviço da agência dos correios, que taxava duplamente as correspondências despachadas de Três Barras.

Depreende-se que o domínio exercido pela Companhia Lumber, no distrito de Três Barras, abrangia diferentes instâncias e se consumava de distintas formas. O resultado era a impossibilidade do usufruto de direitos básicos pela população local.

Não obstante as especificidades do domínio da empresa sobre Três Barras, os momentos de deflagração de greves costumavam ser utilizados pelo patronato para a

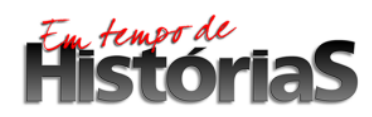


realização de uma varredura entre seus oponentes e adversários políticos, estratagema empregado pela companhia norte-americana quando das greves ocorridas em 1919.

As fontes permitem afirmar que o primeiro semestre de 1919 foi marcado por intensa mobilização dos trabalhadores da Lumber. Ambos os movimentos de março e junho daquele ano, produziram enorme impacto na região, e a ampla repercussão dada àqueles eventos corrobora a afirmação. Do mesmo modo, o período decorrido entre as duas greves também foi de intensa agitação.

Em agosto do mesmo ano, o Jornal A Plebe publicou um resumo dos acontecimentos relacionando-os à greve correspondente ao período de $1 .^{\circ}$ de junho de 1919 a 06 de junho de 1919. Houve uma ampla adesão dos trabalhadores ao movimento. A repressão foi desencadeada pela polícia, com apoio do corpo de segurança da Lumber. Aqueles identificados como principais articuladores do movimento foram demitidos e obrigados a abandonar a localidade, o que não impediu a continuidade da paralisação.

Novamente, o diretor da companhia ameaçou os trabalhadores com um lockout de seis meses, porém, dessa vez, o movimento não arrefeceu, apesar das ameaças, da repressão e das demissões. No quarto dia da greve (04 de junho de 1919), os trabalhadores pretendiam organizar um comício em praça pública. Em resposta, o delegado regional, situado na sacada do prédio da Liga Operária de Três Barras, discursou aos trabalhadores, tentando dissuadi-los de seu intento e convencê-los a retornar ao trabalho, afirmando que “o governo havia de solucionar a questão a seu favor". Ao não obter êxito, tentou chamar os grevistas, um a um, aconselhando-os a voltar ao trabalho. Também fracassou nesse intento. Em resposta, “os operários (...) davam vivas à greve, à solidariedade, e à revolução social". Entrementes, o tenente das forças de repressão "berrou na praça que não admitia gritos e que mandaria varrer o povo à bala", e acrescentou que "o delegado regional não admitia mais nem grupos nem reuniões em parte alguma”.

A partir desse momento, a repressão propagou-se e a polícia tentou conter o movimento por meio da violência e pelo uso da força armada. Iniciaram-se as prisões de grevistas e de desafetos e opositores aos interesses e aliados da Lumber Company, além de ameaças de morte e demissão de dezenas de trabalhadores. Finalmente, a polícia invadiu a sede da Liga Operária e "retirou de lá as bandeiras dos comícios e levou-as para o seu quartel". Três dias depois, aqueles trabalhadores que não foram presos, espancados ou demitidos, retornaram ao trabalho, além de um grande "número de miseráveis que se retiraram para outras paragens". 


\section{Conclusões}

O embate entre os pobres do planalto norte catarinense e as empresas estrangeiras presentes na região, especificamente a Lumber Company, não se restringiu ao período da Guerra do Contestado (1912-1916), mas avançou no tempo e revestiu-se de novas formas, tal qual a mobilização de seus trabalhadores contra os excessos cometidos naquela região pela empresa.

Nesse contexto, apesar das barreiras étnicas advindas da mão de obra de origem estrangeira, em contraposição aos trabalhadores nacionais, as condições inadequadas de trabalho na Lumber Company, que inadvertidamente resultavam em acidentes, vitimando indistintamente todos os trabalhadores, contribuíram decisivamente para suplantar as diferenças e instaurar uma percepção comum de "pertencimento" a um grupo, alicerce de uma futura consciência de classe.

Paulatinamente, com o decorrer dos anos, o estreitamento de relações e vínculos entre os trabalhadores da Lumber, proveniente, naturalmente, do convívio nas práticas laborais, e, inclusive, do modo de vida em comum - externo ao ambiente de trabalho propiciou, conforme sugere a perspectiva thompsoniana, o fortalecimento de uma embrionária consciência de classe, consubstanciada nos momentos de mobilização e luta. Essa união em torno de interesses em comum, quais sejam, assegurar direitos fundamentais a todos os trabalhadores da empresa e suprimir arbitrariedades praticadas pela companhia e pelas autoridades locais por ela cooptadas, atingiu o ápice quando da deflagração dos movimentos grevistas nos anos de 1917 e 1919.

Não obstante os incidentes ocorridos entre os movimentos grevistas, resultantes, dentre outros, de perseguições a membros da Liga Operária, aberturas de inquéritos, ameaças de deportações, ameaça de lockout, disseminação de práticas violentas pelas autoridades locais e pelo corpo de segurança da companhia, é razoável admitir que as greves deflagradas pelos trabalhadores da Lumber estabeleceram, de modo conclusivo, a formação de uma consciência de classe na região do Contestado.

\section{Referências Bibliográficas}




\section{Fontes Primárias}

A Pátria

A Plebe

Gazeta do Povo

O Democrata

O Timoneiro do Norte

\section{Bibliografia}

AUGUSTO, Dídio. In Memoriam. União da Vitória: Uniporto - Gráfica e Editora, 1994 (Coleção Vale do Iguaçu).

CARVALHO, Miguel Mundstock Xavier de. Uma grande empresa em meio à floresta: a história da devastação da floresta com araucária e a Southern Brazil Lumber and Colonization (1870-1970). Tese (Doutorado em História). Universidade Federal de Santa Catarina. Florianópolis, 2010.

DALLANORA, Cristina. Conflito de terra e formas de apropriação no Meio-Oeste Catarinense: o caso de Vivaldino Silveira de Ávila (1916-1930). Conversas \& Controvérsias, v. 4, p. 127-148, 2017.

DIACON, Todd A Milenarian vision, capitalist reality. Brazil's Contestado rebelion, 1912-1916. Durham: Duke University Press, 1991.

ESPIG, Márcia J. Personagens do Contestado: os turmeiros da Estrada de Ferro São Paulo - Rio Grande. Pelotas: Ed. UFPel, 2010.

MACHADO, Paulo Pinheiro. Lideranças do Contestado: a formação das chefias caboclas (1912-1916). Campinas, SP. Editora da Unicamp, 2004.

PAOLI, Maria Célia. "São Paulo operária e suas imagensz (1900-1940)". Espaço e Sociedade: Revista de Estudos Regionais e Urbanos. N. ${ }^{\circ} 33$, ano XI, 1991, p. 27 a 41.

POYER, Viviani. Fronteiras de uma guerra: diplomacia e política internacional em meio ao movimento social do Contestado, 1907-1918. Tese (Doutorado em História). UFSC. Florianópolis, 2018.

RODRIGUES, Rogério Rosa. Veredas de um grande sertão: a Guerra do Contestado e a modernização do Exército brasileiro na Primeira República. Tese de Doutorado em História, Universidade Federal do Rio de Janeiro, Rio de Janeiro, 2008.

SAVAGE, Mike. "Classe e história do trbalho”. In: BATALHA, Cláudio H. M. SILVA, Fernando Teixeira da, e FORTES, Alexandre, (orgs.) Culturas de Classe: identidade e diversidade na formação do operariado. Campinas: Editora da UNICAMP, 2004.

SEYFERTH, Giralda. "Identidade nacional, diferenças regionais, integração étnica e a questão imigratória no Brasil". In: ZARUR, George de Cerqueira Leite. Região e Nação na América Latina. Brasília: Editora da UnB: São Paulo: Imprensa Oficial do Estado, 2000.

SINGER, Paul. O Brasil no contexto do capitalismo internacional (1889-1930). In: História Geral da Civilização Brasileira - 8 - III - O Brasil Republicano - 1 Estrutura de Poder e Economia (1889-1930). Rio de Janeiro: Bertrand Brasil, 1998, p. 381.

THOMPON, Edward Palmer. A Miséria da Teoria ou um Planetário de erros: uma crítica ao pensamento de Althusser. Rio de Janeiro: Zahar, 1978.

Tradición, revuelta y consciencia de clase: Estudios sobre la crisis de la sociedad preindustrial. Barcelona: Editorial Critica. 2. Ed. 1984.

e Terra, 1987.

. A formação da classe operário inglesa. Vols. I, II e III. Rio de Janeiro: Paz

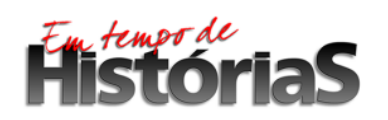

(PPGHIS/UnB) №. 32, Brasília, Jan - Jul 2018 ISSN 2316-1191 
Costumes em comum. Estudos sobre a cultura popular tradicional. Estudos sobre a cultura popular tradicional. São Paulo: Companhia das Letras, 1998.

TOMPOROSKI, Alexandre Assis. “O pessoal da Lumber!” Um estudo acerca dos trabalhadores da Southern Brazil Lumber and Colonization Company e sua atuação no planalto norte de Santa Catarina, 1910 - 1929. Florianópolis. Dissertação (Mestrado em História). Universidade Federal de Santa Catarina. Florianópolis, 2006.

O polvo e seus tentáculos. A Southern Brazil Lumber and Colonization Company e as transformações impingidas ao planalto contestado, 1910-1940. Tese (Doutorado em História). Florianópolis: UFSC, 2013.

Os costumes no planalto catarinense: dos embates no movimento sertanejo do Contestado à luta contra as imposições do capital estrangeiro (1912-1919). Revista Brasileira de História \& Ciências Sociais - RBHCS, Vol. 7, No 14, p.27-56, dez.2015.

VALENTINI, Delmir José. Atividades da Brazil Railway Company no sul do Brasil: a instalação da Lumber e a Guerra na região do Contestado (1906-1916). Porto Alegre. Tese (Doutorado em História). PUC/RS. Porto Alegre, 2009.

VARGAS, João Tristan. O trabalho na ordem liberal: O movimento operário e a construção do Estado na Primeira República. Campinas, SP: UNICAMP/CMU, 2004. 